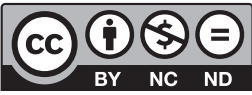

Estudos Teológicos foi licenciado com uma Licença Creative Commons Atribuição - NãoComercial - SemDerivados 3.0 Não Adaptada

http://dx.doi.org/10.22351/et.v60i3.4096

\title{
Terra-Média Na PENUMbra: \\ A NATUREZa teológica do MAL EM $O$ EXPURGo do CONDADO ${ }^{1}$ \\ Middle-earth in half-light: \\ The theological nature of evil in The Scouring of the Shire
}

\section{Alexandre Sugamosto e Silva ${ }^{2}$ Carlos Ribeiro Caldas Filho ${ }^{3}$}

Resumo: $O$ Expurgo do Condado é o oitavo e penúltimo capítulo de $O$ Retorno do Rei e, consequentemente, da trilogia $O$ Senhor dos Anéis, de J. R. R. Tolkien. Entre os fãs e críticos, no entanto, o capítulo é considerado uma incógnita e até mesmo um anticlímax. A adaptação cinematográfica da obra, por exemplo, optou por não filmar o capítulo, porque ele aparentemente quebraria o arco narrativo e o triunfo vitorioso dos hobbits na volta ao lar. Neste artigo, entretanto, trabalharemos com a hipótese de que $O$ Expurgo do Condado exerce um duplo papel sumamente importante na trilogia como um tanto, pois ocupa um espaço fundamental na composição literária de O Senhor dos Anéis quanto parece explicitar a visão que J. R. R. Tolkien tinha acerca da natureza do mal.

Palavras-chave: J. R. R. Tolkien. Teologia e literatura. Natureza do mal.

Abstract: The Scouring of The Shire is the eighth and penultimate chapter of The Return of the King and, consequently, of J. R. R. Tolkien's The Lord of the Rings trilogy as a whole. However, among critics and devotees this chapter is considered as a riddle and even as an anticlimax. The cinematographic adaptation of the book for instance chose not film this chapter because it would apparently break the narrative arc and the triumph of the hobbits on their return home. However, in this article we will work on the hypothesis that The Scouring of the Shire plays a highly important twofold role in the trilogy as a whole, as it occupies a fundamental space in the literary composition of The Lord of the Rings and seems to explain J. R. R. Tolkien's view of evil as well.

Keywords: J. R. R. Tolkien. Theology and literature. Nature of evil.

1 O artigo foi recebido em 15 de agosto de 2020 e aprovado em 06 de novembro de 2020 com base nas avaliações dos pareceristas ad hoc.

2 Mestre. PUC Minas. E-mail: sugamosto@gmail.com

3 Doutor. PUC Minas. E-mail: crcaldas2009@hotmail.com 


\section{Introdução}

John Ronald Reuel Tolkien, ou simplesmente J. R. R. Tolkien, é um dos autores literários mais importantes do século XX. Sua extensa obra, que combina elementos míticos de diversas tradições culturais, tais como a bíblica e a escandinava antiga (para ficar em apenas dois exemplos), é um fenômeno de vendas cujo alcance em diversas esferas da cultura contemporânea parece inesgotável: franquias, filmes, action figures, animações, séries, adaptação para quadrinhos, canções de rock $^{4} .$.

Não bastasse o fenômeno de massas que sua obra alavancou, as criações de Tolkien também fomentaram alguns debates acadêmicos sobre a chamada "questão mitopoética"s. A esse respeito, explica Diego Klautau, especialista brasileiro em temas tolkienianos:

A palavra grega mythopoeia, que significa "fabricar mitos", é o título de um poema de Tolkien ${ }^{6}$ escrito no início dos anos 30, e podemos encontrar essa palavra tanto em Platão, no livro II da República, quanto no capítulo IX na Poética de Aristóteles. No poema de Tolkien, existe um diálogo entre o Philomythus e o Misomythus, entre o que ama e o que odeia os mitos, e a expressão "amante de mitos" (Philomythos) é utilizada por Aristóteles logo no primeiro livro de sua Metafísica, quando associa a admiração dos amantes de mitos com o mesmo maravilhamento necessário ao amante da sabedoria (Philosophos) ${ }^{7}$.

Resumidamente, as querelas intelectuais foram inflamadas pela tentativa tolkieniana de construir um universo próprio, preenchido com línguas inventadas, povos e costumes, de base mitológica. Mas, afinal, Tolkien era apenas um escritor que recolhia espólios de um tempo vencido ou um mitógrafo que estava, de fato, construindo um novo sentido para o imaginário moderno? Um "mito literário artificial" tem a mesma pregnância simbólica de um "mito originário"? De certo modo, o trabalho com os elementos míticos faz com que os livros de Tolkien tenham pontos de contato com diversas obras fulcrais para a literatura moderna, principalmente aquelas de língua inglesa. É preciso lembrar, por exemplo, do método empregado por William Butler Yeats, T. S. Eliot ${ }^{8}$ e James Joyce para criar "um paralelo contínuo entre con-

4 É cristalina, por exemplo, a influência da obra tolkeniana em algumas composições da banda Led Zeppelin. Para informações detalhadas, cf. <https://www.thevintagenews.com/2019/04/05/led-zeppelin-tolkien/>.

5 Há uma pletora de textos que tratam da questão mitopoética em Tolkien. Dentre tantos, é possível citar FLIEGER, Verlyn. Splintered Light: Logos and Language in Tolkien's World. 2nd Revised Edition. Kent: Kent State University Press, 2002; SHIPPEY, Tom. The Road to Middle-Earth: How J. R. R. Tolkien Created a New Mythology. New York: Mariner Books, 2017; FIMI, Dimitri (Org.) Sub-Creating Arda: World-building in J. R. R. Tolkien's, its Precursors and its Legacies. Zollikofen: Walking Tree Publishers, 2019.

${ }^{6}$ O poema de Tolkien está disponível em: $<\mathrm{http} / /$ home.agh.edu.pl/ evermind/jrrtolkien/mythopoeia.htm $>$.

7 KLAUTAU, Diego Genu. Tolkien e suas referências. In: CASAGRANDE, Cristina; KLAUTAU, Diego Genu, CUNHA; Maria Zilda da (Orgs.). A fabricação de mundos. Estudos sobre a literatura de J. R. R. Tolkien. São Paulo: FFLCH/USP, 2019. p. 15.

8 Para detalhes sobre a obra de Eliot consultar KIRK, Russell. A era de T. S. Eliot. A imaginação moral no século XX. São Paulo: É Editora, 2011 e FIMI, 2019. 
temporaneidade e antiguidade" e estabelecer uma "rede complexa de alusões oblíquas e correspondências interculturais"9.

Um olhar sobre o "método mítico" do modernismo (KERMODE, 1975, p. 177), relacionando-o ao trabalho de Tolkien, revela algumas surpreendentes semelhanças entre esses escritores, que até agora não estavam associados um ao outro. Essa comparação mostra que Tolkien não é, como muitos estudiosos afirmam, essencialmente um escritor vitoriano que aconteceu nascer algumas décadas tarde demais; ele era de fato, como Tom Shippey afirma, “um 'autor do século', o século XX, respondendo às questões e ansiedades desse século". ${ }^{10}$

Evidentemente, alguns comentadores literários são reticentes sobre a possibilidade de traçar qualquer comparação entre Tolkien e reformadores do romance e da poesia moderna, como é o caso de Joyce e Eliot. Tal postura se deriva de considerações críticas que tratam a obra de Tolkien como portadora de uma dicotomia estrita entre as forças do Bem e do $\mathrm{Mal}^{11}$ e um suposto fascínio ludita e de glorificação da guerra. Essas asserções surgiram nas primeiras e mais importantes recepções críticas aos livros de Tolkien. Na fileira dos detratores estavam figuras de alto calibre na cultura literária de língua inglesa: Edmund Wilson, Harold Bloom e Michael Moorcock. Ao comentar "O Senhor dos Anéis", Wilson afirmou que certas pessoas, especialmente na Inglaterra, cultivavam há muito tempo um "apetite por lixo juvenil”. Harold Bloom foi ainda mais longe em sua diatribe. Segundo ele, o "Senhor dos Anéis" era "inflado, sobrescrito, tendencioso e moralista ao extremo"12. Michael Moorcock, entretanto, foi o crítico mais contundente da obra tolkieniana e já foi até mesmo chamado de "o anti-Tolkien". Em 1978, Moorcock, importante figura na renovação da ficção científica, escreveu o artigo Epic Pooh, uma paródia explícita com as estórias do "Ursinho Pooh", em que ataca a obra de Tolkien por promover "mitos sentimentais sobre a guerra"13. Em uma entrevista recente, ele diz explicitamente que considera Tolkien um "cripto-fascista", pois "em Tolkien, todos estão em seus lugares e felizes por estarem lá. Nós vamos lá e voltamos, para onde começamos. Não há escapatória, nada jamais mudará e ninguém jamais sairá deste mundo bem ordenado"14.

9 FREER, Scott. The Mythical method: Eliot's 'the waste land' and a Canterbury Tale (1944). Historical Journal of Film, Radio and Television, v. 27, n. 3, p. 357-370, 2007. p. 357.

${ }^{10}$ HILEY, Margaret. Stolen Language, Cosmic Models: myth and mythology in Tolkien. Mfs Modern Fiction Studies, v. 50, n. 4, p. 838-860, 2004. Project Muse. p. 838-839.

${ }^{11}$ GARBOWSKI, Christopher. "Evil". In: LEE, Stuart D. (Ed.). A Companion to J. R. R. TOLKIEN. New Jersey: Wiley-Blackwell, 2014. p. 418.

12 Apud MOONEY, Chris. Kicking the Hobbit. The American Prospect, Washington, D.C., p. 1-1. 05 nov. 2001. Disponível em: <https://prospect.org/features/kicking-hobbit/>. Acesso em: 06 jul. 2020.

${ }^{13}$ MOORCOCK, Michael. Epic Pooh. 1978. Disponível em: <https://warwick.ac.uk/fac/arts/english/ currentstudents/undergraduate/modules/en361 fantastika/bibliography/2.7moorcock_m.1978epic_pooh. pdf $>$. Acesso em: 10 jul. 2020.

${ }^{14}$ HARRISON, Andrew. Michael Moorcock: "I think Tolkien was a crypto-fascist". New Statesman, Londres, p. 1-1, 24 jul. 2015. Disponível em: <https://www.newstatesman.com/culture/2015/07/michael-moorcocki-think-tolkien-was-crypto-fascist>. Acesso em: 03 jul. 2020. 
Como contraponto a essas críticas, pode-se citar um crítico literário do calibre de um C. S. Lewis, que não economizou elogios em sua apreciação de $O$ Senhor dos Anéis (doravante, $S d A$ ):

Provavelmente nenhum livro jamais escrito no mundo seja um exemplo tão radical daquilo que seu autor chamou em outro lugar de "subcriação"15. A dívida direta (há, naturalmente, tipos de dívida mais sutis) que cada autor deve ao universo real é aqui, de modo deliberado, reduzido ao mínimo. Não satisfeito em criar sua própria história, ele cria, com uma prodigalidade quase insolente, o mundo inteiro em que ela transcorre, com sua teologia própria, com seus mitos, geografia, história, paleografia, línguas e ordens de seres - um mundo "repleto de criaturas estranhas". Os nomes, por si só, são um banquete, quer sejam do aromático e tranquilo interior (Grã Cava, Quarta Sul), valentes e majestosos (Boromir, Faramir, Elendil), repugnantes, como Sméagol, que também é Gollum, ou de franzir o cenho com a força maligna de Barad-dûr ou Gorgoroth; ainda melhor (Lothlórien, Gilthoniel, Galadriel) quando eles encarnam aquela beleza élfica penetrante e elevada, da qual nenhum outro escritor de prosa capturou tanto ${ }^{16}$.

O que parece estar em jogo, portanto, são as concepções morais, religiosas e, até mesmo, teológicas de Tolkien, e a forma como elas se manifestam no conjunto de sua obra: há espaço para desordem e caos na mitopoética tolkieniana? Qual é, efetivamente, o papel do Mal nas narrativas de Tolkien? Dentre todas as passagens de sua extensa obra, há uma que parece condensar as percepções sobre essa série de questões profundas com as quais Tolkien se deparou durante a vida: trata-se do capítulo $O E x$ purgo do Condado (The Scouring of the Shire) que integra a parte final de O Retorno do Rei, o livro derradeiro da trilogia O Senhor dos Anéis.

Desse modo, analisaremos como essa passagem se apresenta no livro e quais são os problemas religiosos e teológicos que ela suscita.

\section{O Expurgo do Condado - Contextualização literária do capítulo na obra}

O enredo geral de $O$ Senhor dos Anéis é sobejamente conhecido (seja por conta dos próprios livros, seja pela adaptação cinematográfica de Peter Jackson): Frodo, um jovem hobbit, é chamado para uma missão que envolve a sobrevivência de toda a Terra-Média e posteriormente é escolhido, por um conselho multirracial, como o portador do Anel que deverá ser destruído. A eliminação do Anel, por sua vez, é condição fundamental para que Sauron, a entidade oculta que personifica a potência do mal, não consiga concretizar seus planos de dominação total. Depois de diversas peripécias, o Anel é derretido nas chamas de Mordor, e Sauron é derrotado. Assim, Frodo e os

15 Lewis, neste ponto, faz referência a um dos mais conhecidos e importantes conceitos de Tolkien, que aparece em On Fairy-Stories. Essays Presented to Charles Williams, publicado originalmente em 1947. Para a edição em português, cf. TOLKIEN, J. R. R. Sobre histórias de fadas. São Paulo: Conrad, 2006.

16 LEWIS, C. S. O Senhor dos Anéis, de Tolkien. Sobre histórias. Rio de Janeiro: Thomas Nelson, 2018. p. 147. 
outros hobbits que o acompanharam na saga podem, finalmente, retornar ao seu lugar de origem: o Condado (The Shire). Na já mencionada apreciação crítica que fez a $S d A$, Lewis apresenta o seguinte comentário geral sobre a trilogia:

O tema central de quase todo o livro é o contraste entre os hobbits (ou "o Condado") e o destino terrível ao qual alguns deles são chamados, a descoberta terrível que a humilde felicidade do Condado, que eles pensavam ser certamente normal, é, na realidade, uma espécie de acidente local e temporário, que sua existência depende de sua proteção por poderes que os hobbits não se atrevem a imaginar, que qualquer hobbit pode se ver forçado a sair do Condado e se envolver nesse grande conflito. Mais estranhamente ainda, o advento desse conflito entre coisas mais fortes pode depender, que são quase os mais fracos ${ }^{17}$.

Em todos os livros nos quais o Condado é mencionado, Tolkien nos dá a descrição de um lugar organizado, pacífico, quase idílico, onde reinam a tranquilidade e a boa mesa. Nas primeiras linhas de $O$ Hobbit, por exemplo, lemos: "Numa toca no chão vivia um hobbit. Não uma toca desagradável, suja e úmida, cheia de restos de minhocas e com cheiro de lodo; tampouco uma toca seca, vazia e arenosa, sem nada em que sentar ou o que comer: era a toca de um hobbit, e isto quer dizer conforto"18. Além do conforto, os hobbits também são apreciadores da natureza, do silêncio dos rios, das sombras das árvores e da água cristalina. Por essa razão, essas pequenas criaturas são

[...] capazes de se deliciar com essas coisas simples por elas mesmas e não apenas como um meio para atingir um fim ou como desculpas para alcançar poder. Essa é uma das razões - talvez a razão mais importante - pela qual eles são capazes de resistir à influência sedutora do Anel por tanto tempo: fundamentalmente, eles não se preocupam com as manipulações do poder, então são capazes de tomar as coisas pelo que elas são ${ }^{19}$.

Em certo sentido, portanto, o Condado se apresenta como uma terra não maculada pelas constantes batalhas de poder que se passam na Terra-Média desde o princípio dos tempos. Como não poderia ser diferente, o retorno dos hobbits para casa é cercado de expectativas: eles sonham em rever o lar, os amigos e parentes que deixaram para trás, a boa comida e os lendários e famosos festejos. Há, no entanto, uma tinta melancólica que se anuncia no caminho até o Condado: os hobbits não são mais os mesmos e as violentas pelejas que enfrentaram no mundo das "pessoas grandes" serviram como vetores de transformação de caráter em todos eles. Não é de modo algum surpresa que o mais afetado pela aventura tenha sido Frodo Bolseiro. Por conta do golpe desferido por um Nazgûl, os "Espectros do Anel e os servos mais terríveis

${ }^{17}$ LEWIS, 2018, p. 149.

18 TOLKIEN, J. R. R. O Silmarillion. São Paulo: Martins Fontes, 2002. p. 1.

${ }_{19}$ DICKERSON, Matthew. Ents, Elves, and Eriador: The Environmental Vision of J. R. R. Tolkien. Lexington: The University Press of Kentucky, 2006. p. 13. 
do Inimigo"20, ele carrega consigo uma ferida que conjura o fardo da escuridão. Em um diálogo com Gandalf, Frodo ouve do mago que alguns ferimentos "não podem ser totalmente curados". Resignado, o hobbit responde:

- Temo que esse possa ser o meu caso - disse Frodo. - Não existe um retorno de verdade. Embora eu possa voltar, o Condado não será o mesmo, pois eu não serei o mesmo. Fui ferido por faca, ferrão e dente, sem falar no fardo que carreguei por tanto tampo tempo. Quanto poderei descansar? Gandalf não respondeu ${ }^{21}$.

Embora a narrativa de $O$ Senhor dos Anéis não seja um romance de formação (Bildungsroman ${ }^{22}$,), é possível acompanhar e traçar um arco de desenvolvimento e crescimento da complexidade psicológica de Frodo desde sua saída do Condado até os acontecimentos mais importantes de Mordor. Em certa medida, a chave para a compreensão do "Expurgo do Condado" é a ideia de que ele não será o mesmo porque os próprios hobbits não serão mais os mesmos: a amálgama entre paisagem, terra e criatura, aliás, é decisiva para a ecologia profunda que permeia a literatura tolkieniana. ${ }^{23}$ Desta maneira, pode-se evocar a conhecida frase do filósofo pré-socrático Heráclito de Éfeso (540-470 a.C.) para explicar as transformações que os quatro hobbits aventureiros, especialmente Frodo, e o Condado sofreram: quem entra em um rio não sai na outra margem a mesma pessoa. Depois de tudo que aconteceu, Frodo e o Condado já não eram mais os mesmos.

Mas, afinal, o Condado também era o mesmo? No capítulo do "Expurgo", os heróis hobbits descobrem que não. A terra havia sido tomada por estrangeiros que escravizaram e saquearam a população. Ainda mais: árvores foram cortadas, florestas devastadas e muitos lugares fediam e estavam completamente bagunçados e sujos. Espantando, Sam exclama: "Isso é pior que Mordor!", e continua, "De certa maneira muito pior. A gente sente na própria pele, como se diz; porque aqui é nossa casa, e ficamos lembrando de como era antes de ser toda destruída" ${ }^{24}$.

Coordenados por Merry e Pippin, os hobbits iniciam uma espécie de rebelião fazendo com que "quase setenta rufiões" jazessem mortos no campo e 12 fossem presos. Por outro lado, 19 hobbits morreram na chamada "Batalha de Beirágua", a "última batalha travada no Condado, e a única desde a dos Campos Verdes, em 1147, que ocorrera lá em cima, na Quarta Norte"25. Entretanto, o fato mais inusitado é que o mentor da desordem na terra dos hobbits era ninguém menos do que o mago caído Saruman (com a ajuda de Pústula ${ }^{26}$ ). Expulso do Conselho Branco e da Ordem dos

\footnotetext{
20 TOLKIEN, 2002, p. 368.

21 TOLKIEN, J. R. R. O Senhor dos Anéis. O Retorno do Rei. São Paulo: Martins Fontes, 2001. p. 269.

22 Para uma visão geral sobre o assunto, consultar MORETTI, Franco. The Way of the World: The Bildungsroman in European Culture. Nova York: Verso, 2000.

${ }^{23}$ Cf. DICKERSON, 2006; CURRY, Patrick. Defending Middle-Earth. Tolkien: Myth and Modernity. London: HarperCollins, 1997. p. 26-28.

24 TOLKIEN, 2001, p. 300.

25 TOLKIEN, 2001, p. 298.

${ }^{26}$ Pimple no original.
} 
Istari, Saruman termina a Saga do Anel sem nenhum poder e transformado em uma espécie de "líder miliciano" no Condado. Com sua filosofia pacifista e antiviolência, Frodo oferece clemência e franqueia a partida ao mago decadente por ele já ter sido uma "espécie de nobre contra a qual não deveríamos ousar levantar nossas mãos"27. Antes que ele possa ir embora, porém, é morto por seu servo e espião Grima Língua-de-Cobra (Grima Wormtongue no original).

O capítulo em tela foi excluído da adaptação da trilogia $O$ Senhor dos Anéis para o cinema dirigida por Peter Jackson. Talvez o motivo dessa opção seja pela espécie de anticlímax que a passagem promove na obra: em vez de voltarem para uma terra pacífica em que tudo continua em ordem e harmonia, os hobbits são obrigados a lutar mais uma vez para salvar sua própria terra. Mas então qual é a função geral do "Expurgo" na Saga do Anel? Por conta de diversas especulações sobre possíveis alegorias políticas e referências ao ambiente pós-guerra da Inglaterra, o próprio Tolkien deu pistas para esclarecer o assunto:

Esse capítulo [O Expurgo do Condado] é uma parte essencial do enredo, previsto desde o início, embora neste episódio tenha sido modificado pelo modo como o caráter de Saruman se configura na história, sem, é preciso que eu diga, qualquer significado alegórico ou referência política de qualquer tipo ${ }^{28}$.

Dentre as numerosas possibilidades de intepretação, entretanto, queremos aqui analisar as implicações teológicas levantadas por "O Expurgo do Condado". Para tanto, é necessário, em primeiro lugar, uma mirada geral na visão teológica de Tolkien.

\section{A visão teológica de Tolkien}

A vasta produção literária de Tolkien tem sido analisada a partir de diferentes perspectivas. Dentre tantas, a que receberá atenção nesta seção do artigo é a teológica. Partimos do pressuposto que a fé cristã professada por Tolkien se reflete em seu legendarium, e que qualquer tentativa de interpretação desse conjunto de sua obra que não levar em conta o aspecto teológico será, no mínimo, prejudicada, por não levar em conta o que era simplesmente fundamental para o autor britânico.

Quanto a isso, há que se dizer que este artigo não busca originalidade, pois já há considerável corpus de obras que se debruçaram sobre o mencionado legendarium tolkieniano tomando o ponto de vista teológico como referencial hermenêutico. Tome-se como exemplo Wood, que afirma sem rodeios que o Evangelho é o tema fundamental, o pano de fundo e a esperança implícita na obra de Tolkien ${ }^{29}$. Wood acerta em sua observação, no sentido de que toda a estrutura narrativa do legendarium

27 TOLKIEN, 2001, p. 301.

28 TOLKIEN, J. R. R. The Lord of the Rings. A Foreword to the Second Edition. Nova York: Harper Collins, 1995. p. xxi.

29 WOOD, Ralph C. The Gospel According to Tolkien. Visions of the Kingdom in Middle-earth. Louisville: Westminster John Knox, 2003. p. 1. 
tolkieniano segue as linhas teológicas fundamentais da narrativa bíblica. Em outras palavras: desde $O$ Silmarillion até $O$ Retorno do Rei, que encerra a trilogia de $O \mathrm{Se}$ nhor dos Anéis, encontra-se uma narrativa de criação, queda e redenção. Esse grande arco é encontrado nas Escrituras cristãs, desde o Gênesis até o Apocalipse. De fato, no legendarium tolkieniano veem-se não poucos elementos indubitavelmente calcados na tradição cristã, como que releituras de passagens bíblicas e a apresentação de temas teológicos que servem como cenários para as narrativas da Terra-Média. Por isso torna-se necessária uma nota de esclarecimento, como um disclaimer: o que se segue é não mais que uma apresentação resumida do rico conteúdo teológico que se encontra na obra tolkieniana. Não há pretensão de exaustividade nesta sessão do presente artigo.

Um exemplo do elemento teológico na obra de Tolkien encontra-se no Ainulindalë - A Música dos Ainur, a abertura de $O$ Silmarillion, obra que talvez seja a magnum opus de Tolkien ${ }^{30}$ :

Havia Eru, o único, que em Arda é chamado de Ilúvatar. Ele criou primeiro os Ainur, os Sagrados, gerados por seu pensamento, e eles lhe faziam companhia antes que tudo o mais fosse criado. E ele lhes falou, propondo-lhes temas musicais; e eles cantaram em sua presença, e ele se alegrou ${ }^{31}$.

O texto de $O$ Silmarillion faz lembrar um texto bíblico como "No princípio criou Deus os céus e a terra" (Gn 1.1). É bem verdade que em Tolkien os temas e as imagens de inspiração bíblica são apresentados de maneira por demais sutil. Não há em seus textos alegorias de interpretação quase óbvias, como é o caso bastante conhecido do leão Aslan, alegoria explícita de Jesus nas Crônicas de Nárnia, de C. $\mathrm{S}$. Lewis, amigo e colega de Tolkien. Portanto não há um personagem com características cristológicas no legendarium. Antes, há o que se denomina de "cristologia fragmentada", isto é, diferentes personagens com traços que podem ser entendidos como tendo sido inspirados por textos bíblicos relacionados a Jesus, o Messias cristão. ${ }^{32}$ Esses diferentes personagens não são alegorias de Jesus, como o mencionado leão Aslan de Nárnia, mas figuras, ou tipos, conforme exposto pelo crítico literário alemão Erich Auerbach, que explica como os escritores do Novo Testamento leram a Bíblia Hebraica, tomando a pessoa de Jesus de Nazaré como chave de leitura:

A interpretação figural transformou o Velho Testamento de livro de leis e da história do povo de Israel numa série de prefigurações de Cristo e da Salvação tal como encontramos mais tarde na procissão dos profetas no teatro medieval e nas representações cíclicas da escultura medieval ${ }^{33}$.

${ }^{30}$ Para detalhes quanto a uma leitura de $O$ Silmarillion a partir de uma perspectiva dos estudos de religião e da teologia, cf. CALDAS FILHO, C. R. Religião e Literatura - Reflexões sobre O Silmarillion. Ciências da Religião, São Paulo, v. 1, n. 1, p. 135-156, 2003.

${ }^{31}$ TOLKIEN, 2002, p. 3.

${ }^{32}$ CALDAS FILHO, 2003.

33 AUERBACH, Erich. Figura. São Paulo: Ática, 1997. p. 45. 
Seguindo Auerbach, e usando o conceito de interpretação figural, é possível encontrar em diferentes personagens na grande narrativa de $S d A$ elementos, características ou facetas que apontam para um ou outro aspecto da vida de Jesus. Conforme Caldas Filho,

[...] por isso é possível dizer que em $O$ senhor dos anéis há uma cristologia fragmentada, difusa e dispersa, no sentido de que diversos personagens apresentam vários aspectos da pessoa e da obra do Cristo dos Evangelhos canônicos cristãos. Gandalf que se sacrifica para que os companheiros de jornada possam escapar do ataque do Balrog, mas volta à vida, embora de maneira diferente, não sendo reconhecido de imediato pelos amigos (tal como os relatos evangélicos sobre a ressurreição de Jesus, que dizem que ele não foi reconhecido de imediato, por exemplo, pelos caminhantes da estrada de Emaús ou por Maria Madalena), Aragorn, desprezado [...], aparentemente um "qualquer", mas que na verdade, a despeito de sua aparência simples e humilde, é um rei (tal como a profecia de Isaías a respeito do Messias que viria, o apresenta como alguém que não é imediatamente identificado como tal), Frodo, que carrega o fardo do "Um Anel", símbolo do vício, da maldade e da corrupção, até o lugar onde este pode ser destruído (tal como as epístolas do Novo Testamento vão interpretar o significado e os resultados da morte de Jesus na $\mathrm{cruz}^{34}$.

Outros elementos de uma Weltanschauung cristã podem ser encontrados ao longo de toda a literatura de fantasia do legendarium de Tolkien, tais como a crença em um Deus eterno criador de todas as coisas e realidades (Eru, o Único), a existência de criaturas espirituais - os Ainur, os valar e os maiar ${ }^{35}$ - que servem a Eru, o que faz lembrar a hierarquia celestial de anjos, arcanjos, querubins e serafins $s^{36}$ da tradição cristã $\tilde{3}^{37}$, a descrição de uma "queda", isto é, desobediência ao mandato do Deus Úni-

${ }^{34}$ Proposta de leitura teológica da mitologia de J. R. R. Tolkien. In: CALDAS FILHO, C. R. (Org.). $O$ Evangelho da Terra-Média. Leituras teológico-literárias da obra de J. R. R. Tolkien. São Paulo: Mackenzie, 2011. p. 51-52.

${ }^{35}$ Todavia, quanto aos Ainur, os valar e maiar de Tolkien há que se destacar que se tratam de criações complexas, pois agregam a um só tempo uma influência da tradição judaico-cristã com elementos inspirados nas mitologias greco-romana e nórdica (cf., inter alia, CORREIA, Fernanda da Cunha. O Silmarillion: a biografia de uma obra. In: CASAGRANDE; KLAUTAU; CUNHA (Orgs.), 2019, p. 64), pois os seres espirituais tolkienianos são como que deuses menores que o "Pai de todos". Ao mesmo tempo, eles têm poder derivado de Eru, ou seja, não são independentes e autônomos, e não são cultuados nem invocados pelos humanos. A mescla sutil e sofisticada de uma tradição pagã com uma tradição cristã é uma marca da genialidade de Tolkien.

${ }^{36}$ A obra clássica que apresenta a visão medieval cristã sobre a hierarquia dos seres angelicais é a de Dionísio Pseudo-Areopagita (2015). O Pseudo-Dionísio influenciou decisivamente autores como Dante Alighieri, na Divina Comédia, e o mencionado C. S. Lewis, em sua trilogia cósmica ou trilogia espacial (Além do planeta silencioso, Perelandra e Aquela fortaleza medonha).

${ }^{37}$ Em uma carta escrita a Milton Wadman, da editora Harper Collins, escrita provavelmente em 1951 (a carta não traz menção de data), o próprio Tolkien explica que os valar são "poderes angelicais" que atuam na Terra-Média com autoridade delegada em esferas de domínio e governo, mas não de criação CARPENTER, Humphrey; TOLKIEN, Christopher (Eds.). As cartas de J. R. R. Tolkien. Curitiba: Arte \& Letra, 2006. p. 143. 
$\mathrm{co}^{38}$, a derrota do mal introduzido em Arda (= a Terra) por Melkor "não por força nem por violência" (cf. Zc 4.6), mas pelos hobbits, os mais frágeis e indefesos dos povos livres da Terra-Média. ${ }^{39}$ Frodo, o hobbit, é o herói improvável dentre todos os heróis improváveis. A vitória sobre o mal pela instrumentalidade de um pequenino hobbit é como que um eco de uma das palavras paradoxais de Jesus no sermão da montanha: são os "mansos" que herdarão a terra (Mt 5.5, citando Sl 37), não os violentos e poderosos. Ao ler a narrativa tolkieniana, é impossível não se lembrar das palavras de Paulo escrevendo aos cristãos da cidade de Corinto: "Deus escolheu as coisas humildes do mundo, e as desprezadas e aquelas que não são, para reduzir a nada as que são" (1Co 1.28). Talvez seja esta a característica teológica mais notável em SdA: a providência divina atuando por detrás e acima dos acontecimentos, como que em uma tapeçaria que é tecida e vai formar um quadro com uma imagem de bondade e beleza. Em $S d A$, o nome de Eru não aparece, não há menção a rituais religiosos, preces e invocações não lhe são dirigidas, mas a providência divina está presente. Desta maneira, $S d A$ faz lembrar o livro bíblico de Ester, em que o nome de Deus não é mencionado nem uma vez, mas a história é narrada apresentando acontecimentos que parecem ser mero acaso, conduzindo todavia à vitória do bem. Assim como Javé no livro de Ester, Eru é na narrativa do $S d A$ uma "presença ausente" ou uma "ausência presente".

Resumindo: diversos temas teológicos são encontrados na narrativa de Tolkien em seu legendarium. Um desses, a eucatástrofe (literalmente, "boa catástrofe"), termo que aponta para a vitória do bem e a derrota do mal, criado pelo próprio Tolkien em seu já citado texto On Fairy Stories. ${ }^{40}$ Nesse texto, Tolkien apresenta a eucatástrofe como elemento da mitopeia ${ }^{41}$, a construção de mitos $^{42}$. A eucatástrofe tolkieniana, que não deve ser confundida com a noção de deus ex machina do antigo teatro grego, a solução inesperada para um problema (aparentemente) insolúvel. Em Tolkien o que se encontra é uma visão baseada na já mencionada doutrina cristã da providência e a visão da esperança escatológica cristã: o mal será derrotado.

38 Esse tema aparece na mencionada sessão inicial de $O$ Silmarillion, quando movido por inveja e orgulho Melkor introduz uma dissonância na música dos Ainur na presença de Eru.

39 Um representante de cada um dos povos livres da Terra-Média - humanos, elfos, anões - é escolhido para levar o Um Anel para ser destruído na Montanha da Perdição, onde fora forjado milênios antes. O grupo é liderado por Gandalf o Cinzento (que mais tarde será Gandalf, o Branco), um dos Istari, isto é, alguns maiar vieram a Terra-Média na forma de sábios chamados de "magos".

40 TOLKIEN, J. R. R. The Monsters and the Critics and Other Essays. London: HarperCollins, 1990. p. 109-161.

${ }^{41}$ Neste artigo, ao se referir à subcriação tolkieniana, usam-se os termos mitopoética e mitopoeia, que mantêm consonância com a forma mythopoeia do original, por entender que há equivalência conceitual entre os mencionados termos.

42 Sobre a construção de mitos levada a cabo por Tolkien, vale citar uma vez mais Lewis, que teceu a esse respeito comentário conciso e judicioso: “A mitopeia, afinal, não é a mais, e sim a menos subjetiva das atividades?" (LEWIS, 2018. p. 151.) 


\section{A natureza do mal em $O$ Expurgo do Condado}

Para compreender a relação do Mal com O Expurgo do Condado é preciso examinar as figuras de Saruman e Sauron, que concentram os poderes malignos em $S d A$. Comecemos por Sauron, o espectro que deseja recuperar o poder do Um Anel para dominar todos, o "olho" que articula a guerra total desde Barad-dûr (a maior edificação da Terra-Média construída após a queda de Númenor). Entretanto, para compreender melhor sua natureza e origem é preciso levar em conta o amplo quadro narrativo no quão $1 S d A$ se insere. Como já mencionado, em $O$ Silmarillion, Tolkien nos apresenta uma coleção mitopoética, uma narrativa cosmogônica e também os personagens das duas eras que antecederam a Saga do Anel. No Valaquenta, por exemplo, o autor nos dá a relação dos Valar, dos Ainur/Maiar e também dos assim chamado Inimigos. Nessa perspectiva, o nome de Sauron, também conhecido como Gorthaur, o Cruel, está diretamente ligado ao de Melkor, Aquele que se Levanta Poderoso, de quem foi servo. Na cosmogonia tolkieniana, Melkor - posteriormente chamado apenas de Morgoth, O Sinistro Inimigo do Mundo. Segundo o relato do Valaquenta,

[Melkor] Dispunha dos poderes e conhecimentos de todos os outros Valar, mas os desviava para objetivos perversos e desperdiçava sua força em violência e tirania. Pois cobiçava Arda e tudo o que nela existia, desejando a realeza de Manwë e o domínio sobre os reinos de seus pares ${ }^{43}$.

Violência, tirania, cobiça, anseio por dominar: de forma sintética e objetiva, Tolkien apresenta um painel expositivo sobre a natureza do mal. Não se trata, no entanto, apenas de uma perspectiva moral sobre o tema. Tolkien elenca a violência e a cobiça como ideias teológicas que estão no centro dos gestos criadores que deram forma ao Mundo que É (Eä, ou o Universo). De certo modo, a dissonância criada por Melkor na música de Eru Iluvátar é o fator desencadeador das narrativas dramáticas que desaguarão na Saga do Anel. Entretanto, seus atos não têm autonomia absoluta, pois sempre estão mediados e limitados pela vontade de Eru: "E tu, Melkor, verás que nenhum tema pode ser tocado sem ter em mim sua fonte mais remota, nem ninguém pode alterar a música contra a minha vontade" 44 . Por meio dessa concepção, Tolkien parece ecoar a noção teológica de que não existe nada no universo que seja intrinsecamente negativo. Outro ponto teológico que se encontra aí é que, por motivos não explicados, o mal não tem autonomia absoluta. A frase citada acima dita a Melkor também faz lembrar o relato do livro bíblico de Jó: conforme a narrativa desse livro, o Satã ("adversário" em hebraico) faz mal a Jó apenas nos limites impostos ou estabelecidos por Deus (cf. Jó 1.12; 2.6). Pode-se a partir daí compreender que, para Tolkien, o Mal deve sempre ser definido como um rebaixamento, uma desproporção e uma desarmonia. Do ponto de vista literário, o surgimento do Mal funciona também

${ }_{43}$ TOLKIEN, 2001, p. 23.

44 TOLKIEN, 2001, p. 6. 
como um arquétipo. Conforme a tradição crítica, um arquétipo é uma figura ideal de caráter universal que se manifesta em diversos textos com roupagens distintas, mas mantendo uma ideia central sobre sua natureza última. Dessa forma, o velho sábio, o círculo, a rosa, o paraíso perdido, a criança e o herói-criança, a mãe etc., atuariam como elemento diretivo em algumas semânticas narrativas e estariam presentes em diversas lendas, sagas e romances. Gilbert Durand, antropólogo e criador da chamada "arquetipologia", compreende o Imaginário como o "conjunto das imagens e das relações de imagens que constituem o capital do homo sapiens. De sua coleta de imagens, ele retira uma série de conjuntos constituídos em torno de núcleos organizadores (constelações e arquétipos) ${ }^{\prime 45}$. Nessa perspectiva, o Mal também pode aparecer nas narrativas como uma estrutura arquetípica:

Há uma primeira batalha fundamental para a origem de toda história mítica, mitológica, uma situação complexa com elementos naturalmente adversos que, sob uma incitação inerente ao nosso estado, se desencadeia para introduzir na história da humanidade o Mal ou a Temporalidade e a suas consequências ${ }^{46}$.

Compreendendo essa perspectiva teológica, e sua continuidade narrativa em $S d A$, é possível interpretar o rebaixamento de Saruman no capítulo de $O$ Expurgo do Condado como uma espécie de situação exemplar sobre o tema. Quando Frodo encontra Saruman no Condado, com "aparência bem-alimentada e satisfeita" e os olhos reluzindo "malícia e deleite", o mago caído diz: "Mas é evidente que não me esperavam ver aqui" ${ }^{47}$. Frodo, então, responde rispidamente: “- Eu não esperava [...]. Mas poderia ter adivinhado. Uma maldadezinha no estilo mais mesquinho"48. A imagem do outrora poderoso Mago Branco absorvido em deleite por conta de pequenas maldades e tiranias contra um povo autárquico e indefeso retrata o processo de amesquinhamento que o arbítrio pode produzir nas criaturas que sentem atração pelo Mal. Saruman, entretanto, em nenhum momento se dá conta de sua condição espiritual. Na sequência da narrativa, ele conjura: "Mas não pensem que porque perdi todas as minhas posses perdi também meu poder! Qualquer um que me atacar será amaldiçoado!"49. Nessa hora, Frodo lembra aos outros hobbits que Saruman está apenas tentando amedrontá-los com ameaças, que, na verdade, não passam de palavras vazias, como cascas ocas de uma cigarra: "Não acreditem nele. Não lhe resta nenhum poder, exceto a voz, que ainda pode intimidá-los e enganá-los, se permitirem" ${ }^{50}$. Evidentemente, as imprecações eram apenas os últimos balbucios desesperados do personagem. Frodo o expulsa de Hobbiton (a vila dos hobbits), e ele chama Língua de Cobra para que o acompanhe. Frodo franqueia a Grima a possiblidade de ficar por um tempo no Condado, mas Saru-

\footnotetext{
${ }^{45}$ CEMIN, Arneide. Entre o cristal e a fumaça: afinal o que é imaginário? Presença. Revista de Cultura e Meio Ambiente, Porto Velho, Fundação Universidade Federal de Rondônia, v. 5, n. 14, p. 62-68, dez. 1998.

46 BRUNEL, Pierre. Dicionário de Mitos Literários. Rio de Janeiro: José Olympio, 1997. p. 90.

${ }^{47}$ BRUNEL, 1997, p. 300.

48 BRUNEL, 1997, p. 300.

49 TOLKIEN, 2001, p. 301.

50 TOLKIEN, 2001, p. 301.
} 
man intervém "entregando" um crime cometido por seu servo. Os acontecimentos que se seguem são dramáticos. As citações são importantes e úteis para uma compreensão do "ponto" que o artigo apresenta:

- Língua de Cobra! - chamou Frodo. - Você não precisa segui-lo. Não conheço mal algum que me tenha feito. Pode ter descanso e comida aqui por um tempo, até estar mais forte para seguir seus próprios caminhos. Língua de Cobra parou e olhou para trás, meio propenso a ficar. Saruman virou-se: - Mal algum? - grasnou ele. Ah, não! Mesmo quando ele escapa furtivamente durante a noite, é só para apreciar as estrelas. Mas ouvi alguém perguntar onde o pobre Lotho ${ }^{51}$ está escondido? Você sabe, não é mesmo Língua? Vai contar a eles?

Língua de Cobra se encolheu e choramingou: - Não, Não!

Então conto eu - disse Saruman - Língua matou o seu Chefe, pobre criatura, o seu bom Patrãozinho. Não é verdade, Língua? Apunhalou-o enquanto dormia, acho. Enterrou-o, espero [...] Não, Língua não é bonzinho de verdade. É melhor que o deixem para mim. Uma faísca de ódio alucinado brilhou nos olhos vermelhos de Língua de Cobra - Você me mandou fazer isso, você me obrigou - chiou ele. ${ }^{52}$

A passagem mostra, mais uma vez, a tentativa de Frodo em manter o Mal afastado e ser fiel ao seu pacifismo radical. O que Frodo parece não aceitar, entretanto, é a natureza irracional do Mal. Sendo irracional, ele também não cede a ponderações e avisos sobre justiça e equanimidade. A guerra justa, portanto, não tem lugar aí. Em um nível microcósmico, $S d A$ sempre aponta para o seguinte problema moral: o poder é corruptivo por si só? Como bem percebeu Christopher Gadowski (2014), a questão do desejo pelo poder e suas consequências é fulcral para que se possam compreender as motivações de Sauron e Saruman. O ódio surge, então, como uma faísca que alucina e tem consequências fatais:

Saruman riu. - Você sempre faz o que Charcote manda, não é Língua? Bem, agora ele diz: em frente! Chutou Língua de Cobra no momento que este rastejava, virou-se e partiu. Mas nesse momento algo se partiu: de súbito Língua de Cobra se levantou sacando uma faca escondida e então, rosnando como um cachorro, saltou sobre as costas de Saruman, puxou-lhe a cabeça para trás, cortou-lhe a garganta e com um grito correu descendo a ladeira. Antes que Frodo pudesse se recuperar ou dizer alguma coisa três arcos hobbits zuniram e Língua de Cobra caiu morto ${ }^{53}$.

Depois da morte de Saruman, Frodo olhou para o corpo em decomposição com "pena e terror, pois enquanto olhava pareceu que de repente longo anos de morte se revelavam nele" 54 . De acordo com Tom Shippey, um dos principais intérpretes da

\footnotetext{
${ }^{51}$ Lotho é o nome do já citado Pústula. O apelido nada lisonjeiro foi-lhe dado pelas crianças hobbits devido a um defeito que ele tinha na face (cf. TYLER, J. E. A. The Tolkien Companion. New York: Avon Books, 1977. p. 275).

52 TOLKIEN, 2001, p. 301.

53 TOLKIEN, 2001, p. 302.

54 TOLKIEN, 2001, p. 302.
} 
obra tolkeniana, $S d A$ combina duas visões distintas sobre o Mal: uma fundamentada nas filosofias de Boécio e Agostinho, que considera o Mal como "não existente" em sentido apriorístico (tal como anteriormente apresentado), e a outra que se baseia no maniqueísmo: o Mal então entendido como uma força externa que deve ser enfrentada. ${ }^{55}$ Considerando que J. R. R. Tolkien não está construindo um sistema teológico, e sim uma obra de ficção, é natural que certas tensões filosóficas não estejam totalmente resolvidas em seus livros. Muito mais do que uma resposta sobre a natureza última do Mal, Tolkien apresenta a seus leitores a complexidade dessa temática.

Outro eixo temático, contudo, parece conectar a visão tolkieniana do Mal com os acontecimentos de $O$ Expurgo do Condado: a destruição da natureza pela técnica. Conforme é descrito em As Duas Torres (o segundo volume da trilogia), Sauron e Saruman constroem diversas máquinas, aparatos industriais, engenhos e sistemas com o único propósito de dominar a Terra-Média. No início deste artigo mencionou-se, posto que apenas en passant, que Tolkien foi acusado de ser "ludita", ou seja, de renegar todos os avanços industriais e tecnológicos em favor de uma visão ingênua da vida natural. Essa crítica, entretanto, não alcança a importância da dimensão ecológica na obra tolkieniana. Nas chamadas "Terras Imortais" (Aman), duas árvores eram a luz e o poder do mundo: Laurelin, cujo significado do nome é "Ouro", e Telperion, a "Prata". Por inveja da luz esplêndida, e também por ressentimento, Melkor destruiu as duas árvores e as ressecou e "abateu-se assim sobre Valinor a grande escuridão" 56 . A luz das árvores, todavia, deu origem aos dois grandes luzeiros, o Sol e a Lua, em uma passagem que se espelha no excerto bíblico: "Deus fez os dois luzeiros maiores: o grande luzeiro como poder do dia e o pequeno luzeiro como poder da noite, e as estrelas" (Gn 1.16). Foi também com a luz das árvores que Fëanor ${ }^{57}$ criou as "Silmarils", joias luminosas de poder que tiveram um papel preponderante nos desdobramentos históricos da Terra-Média. Tolkien reforça que a degradação ambiental do Condado, a sujeira e a fealdade trazidas por Saruman, não se trata apenas de um juízo moral sobre o problema da técnica, mas sim de uma mirada profunda sobre o papel da natureza como elemento mediador entre os seres manifestados e o mundo paradisíaco. Assim, se a luz é banida e a escuridão se aprofunda, a Terra passa a ser dirigida pela força cega do consumo. Assim, no $O$ Expurgo do Condado:

Temos um vislumbre dessa forma de Mal que penetra no Condado e pensamos imediatamente em nossas próprias casas. Vemos a destruição de lares antigos e a construção de novos, não porque exista algo de errado com os antigos, mas simplesmente porque, de acordo com os padrões de inovação e progresso, o novo deve ser melhor e, portanto,

${ }^{55}$ Citado por HOUGHTON, John William; KEESEE, Neal K. Tolkien, King Alfred, and Boethius: Platonist Views of Evil in the Lord of the Rings. Tolkien Studies, v. 2, n. 1, p. 131-159, 2005. Project Muse. p. 131.

${ }^{56}$ TOLKIEN, 2001, p. 85.

${ }^{57} \mathrm{Na}$ mitologia tolkieniana, Fëanor era o Senhor de uma das principais casas dos Noldor na Primeira Era, talvez o maior de todos os Altos Elfos, famoso por sua habilidade como artesão. Para detalhes, cf. Fëanor in: TYLER, 1977, p. 171-173. 
preferível. Em nosso mundo, quando a habitação e a construção indústrias consomem recursos, é importante "estimular a economia", ou é o que nos dizem ${ }^{58}$.

Ora, sendo assim, não há nada de "tolo" ou ingênuo na apreciação explícita de Tolkien sobre o papel deformador do progresso no ambiente idílico do Condado. Afinal, ela é acompanhada por uma perspectiva cosmogônica e teleológica que se espraia pelos motivos condutores de $S d A$. Quando Sauron e Saruman mergulham no "mundo da técnica" (Ge-stel), eles o fazem justamente por cobiça e por uma reminiscência de como os poderes da criação se organizaram in illo tempore. A cobiça e a vontade de poder, que se transformam em violência e tirania posteriormente, são, portanto, as motivações que rebaixam os Ainur do mundo da luz ao mundo da penumbra perpétua. O Expurgo do Condado demonstra, portanto, que não há lugar na Terra-Média que não seja tocado pela degradação e pela corrupção. Parafraseando Agostinho, em $S d A$ concluímos que só a Civitate Dei pode ser, de fato, sem mácula. ${ }^{59}$ Não se pode esquecer que Tolkien é bastante influenciado por Agostinho ${ }^{60}$, particularmente (mas não apenas) na compreensão agostiniana do mal como privação do bem. ${ }^{61} \mathrm{Em}$ Agostinho (2006), seguido por Tolkien, a salvação acontece por Deus e em Deus, ou seja, por uma operação livre da graça divina, o que contrasta claramente com qualquer promessa prometeica de salvação por meio da técnica e da tecnologia.

Por fim, é preciso ressaltar um outro aspecto relevante de O Expurgo do Condado: Tolkien é um mitólogo e não um fabulista. Seus livros, portanto, são compostos por extratos e reinvenções de antigas sagas, principalmente as de matriz nórdica. ${ }^{62}$ Sendo assim, o fato de os hobbits precisarem lutar por sua própria terra depois de enfrentarem jornadas perigosas no mundo dos "homens grandes" não é um adendo literário sem propósito. A luta constante dos seres por sua própria existência é um leitmotiv recorrente nos materiais míticos e Tolkien não abre mão de inserir esse elemento em sua composição. Se o Mal, conforme já mencionado, é um rebaixamento e uma deformação, ele, entretanto, também assume formas sutis em suas dissimulações. Quando ainda estava planejando a queda de Númenor, no princípio da Terceira Era, Sauron estendeu sua sede de poder aos confins da Terra-Média. Por isso ele

${ }_{58}$ DICKERSON, 2006, p. 70.

${ }^{59}$ Não se pode esquecer que Tolkien foi influenciado pelo pensamento teológico-filosófico de Agostinho de Hipona. Para detalhes, consultar KLAUTAU, Diego Genu. O Bem e o Mal na Terra-Média - A filosofia de Santo Agostinho em O Senhor dos Anéis de J. R. R. Tolkien como crítica à modernidade. 2007. Dissertação (Ciências da Religião) - Programa de Pós-Graduação em Ciências da Religião da Pontifícia Universidade Católica de São Paulo, São Paulo, 2007.

${ }^{60}$ Cf. KLAUTAU, 2007, p. 135, 154.

${ }^{61}$ Nas Confissões, Agostinho declara: "Procurei o que era a maldade e não encontrei substância, mas sim uma perversão da vontade desviada da substância suprema"'(SANTO AGOSTINHO. Confissões. São Paulo: Abril Cultural, 1973. (Coleção Os Pensadores). p. 142). Em outras palavras: o mal não tem substância própria.

${ }^{62}$ Cf. FIMI, Dimitra. Tolkien and Old Norse Antiquity: Real and Romantic Links in Material Culture. In: CLARK, David; PHELPSTEAD, Carl (Eds.). Old Norse Made New: Essays on the Post Medieval Reception of Old Norse Literature and Culture. London: University College London; Viking Society for Northern Research, 2007. p. 83-99. 
Não tolerava nenhuma liberdade nem rivalidade e se intitulou Senhor da Terra. Uma máscara ainda conseguia usar para poder enganar os olhos dos homens, se quisesse, parecendo-lhes sábio e belo. No entanto, governava mais pelo medo e pela força, se esses pudessem resolver ${ }^{63}$.

Por isso, para enfrentar as articulações malévolas é preciso amadurecimento e olhos para enxergar as intenções que se ocultam sob a máscara. Em $O$ Expurgo do Condado, os quatro hobbits, agora soldados experientes e valorosos, não demoram a entender o que estava acontecendo em sua terra e articulam uma resposta rápida e objetiva para extirpar o Mal que os assombrava. É curioso notar que até Saruman reconhece o quanto os hobbits "cresceram": dirigindo-se a Frodo, ele diz "Você cresceu, Pequeno - disse ele. Sim, você cresceu muito"64. O que foi dito em relação a Frodo aplica-se aos seus amigos Merry e Pippin, e especialmente a Sam. Não é por uma exaltação "abstrata" da guerra que Tolkien descreve numerosas batalhas e mortes, mas pelo imperativo que jaz na própria natureza do mundo. O Mal pode, sim, ser vencido e a eucatástrofe alcançada. Para que isso ocorra, contudo, é preciso combatê-lo.

\section{Considerações finais}

O Expurgo do Condado é um fechamento adequado ao grande conjunto de $S d A$, absolutamente coerente com toda a narrativa que o antecede. Nesse capítulo encontram-se temas importantes de inspiração cristã, a saber, a misericórdia e o perdão. Frodo é misericordioso e compassivo para com Saruman e Língua de Cobra. Esses rejeitam a oferta de perdão que recebem, mas por decisão livre que tomaram. Talvez Frodo pensasse que, assim como Sméagol/Gollum fora poupado, e acabou, ainda que de maneira involuntária e indireta, servindo ao grande propósito da destruição do Um Anel, o mesmo pudesse acontecer com Saruman. Ainda que tal não tivesse acontecido, como visto no ponto anterior deste artigo, mesmo assim, Frodo ofereceu graça a Saruman e a Grima Língua de Cobra. Graça, na famosa definição do já citado bispo de Hipona, não sem razão denominado Doctor Gratiae, é “favor não merecido". Desnecessário dizer que nem Grima nem Saruman mereceriam qualquer tratamento compassivo. Eis aí a enigmática e escandalosa mensagem teológica da graça: o perdão e a compaixão oferecidos a quem de modo algum merece. Saruman rejeita a oferta da graça por conta de seu orgulho. Por conta de sua atitude soberba e de sua recusa de se humilhar para aceitar o perdão oferecido por Frodo, diz ao hobbit: "odeio você e sua clemência!"'65. E mais uma vez há que se lembrar de Agostinho, que disse ser o orgulho o pior e o principal de todos os pecados. A antiga tradição cristã, que vem dos tempos da Patrística, atribuía ao orgulho a razão da queda do arcanjo que viria a ser o "adversário": por não querer se humilhar a ponto de pedir perdão, foi expulso

\footnotetext{
63 TOLKIEN, 2001, p. 369.

64 TOLKIEN, 2001, p. 302.

${ }_{65}$ TOLKIEN, 2001, p. 302.
} 
da presença divina. Como visto na parte inicial deste artigo, a queda de Morgoth "o Inimigo" também se deu por orgulho e soberba. Saruman e seu servo Grima Língua de Cobra acabam por seguir esse mesmo caminho ao rejeitar a graça que lhes é oferecida.

Finalizando: Tolkien, escritor de profundidade oceânica, apresenta com sutileza e requinte literário a mensagem cristã que não nega a realidade do mal e apresenta como esse deve ser combatido. Pelos caminhos misteriosos e, não raro, inexplicáveis e incompreensíveis da providência, o mal é derrotado. Contudo, há a oferta de perdão mesmo para os piores agentes da maldade. A oferta é válida, e só não se efetivará se esses agentes, por orgulho, a recusarem.

\section{Referências}

SANTO AGOSTINHO. Confissões. São Paulo: Abril Cultural, 1973. (Coleção Os Pensadores). AGOSTINHO. A natureza do bem. Rio de Janeiro: Sétimo Selo, 2006.

AUERBACH, Erich. Figura. São Paulo: Ática, 1997.

BEBERGAL, Peter. The Anti-Tolkien. The New Yorker. New York, p. 1-1. 31 dez. 2014. Disponível em: <https://www.newyorker.com/books/page-turner/anti-tolkien>. Acesso em: 10 jul. 2020. BIRNS, Nicholas. "You have grown very much": The Scouring of the Shire and the novelistic aspects of the Lord of the Rings. The Free Library. 01 January 2012. 07 July 2020. Disponível em: <https://www.thefreelibrary.com/"You have grown very much":The Scouring of the Shire and the...-a0298173246>.

BRUNEL, Pierre. Dicionário de Mitos Literários. Rio de Janeiro: José Olympio, 1997.

CALDAS FILHO, C. R. Religião e Literatura - Reflexões sobre O Silmarillion. Ciências da Religião, São Paulo, v. 1, n. 1, p. 135-156, 2003.

CALDAS FILHO, C. R. Proposta de leitura teológica da mitologia de J. R. R. Tolkien. In: CALDAS FILHO, C. R. (Org.). O Evangelho da Terra-Média. Leituras teológico-literárias da obra de J. R. R. Tolkien. São Paulo: Mackenzie, 2011.

CARPENTER, Humphrey; TOLKIEN, Christopher (Eds.). As cartas de J. R. R. Tolkien. Curitiba: Arte \& Letra, 2006.

CEMIN, Arneide. Entre o cristal e a fumaça: afinal o que é imaginário? Presença. Revista de Cultura e Meio Ambiente, Porto Velho, Fundação Universidade Federal de Rondônia, v. 5, n. 14, p. 62-68, dez. 1998.

CORREIA, Fernanda da Cunha. O Silmarillion: a biografia de uma obra. In: CASAGRANDE, Cristina; CURRY, Patrick. Defending Middle-Earth. Tolkien: Myth and Modernity. London: HarperCollins, 1997.

DICKERSON, Matthew. Ents, Elves, and Eriador: The Environmental Vision of J. R. R. Tolkien. Lexington: The University Press of Kentucky, 2006.

DIONÍSIO PSEUDO-AREOPAGITA. A hierarquia celeste. São Paulo: Polar, 2015.

FIMI, Dimitra. Tolkien and Old Norse Antiquity: Real and Romantic Links in Material Culture. In: CLARK, David; PHELPSTEAD, Carl (Eds.). Old Norse Made New: Essays on the Post Medieval Reception of Old Norse Literature and Culture. London: University College London; Viking Society for Northern Research, 2007. p. 83-99.

FIMI, Dimitri (Org.). Sub-Creating Arda: World-building in J. R. R. Tolkien's, its Precursors and its Legacies. Zollikofen: Walking Tree Publishers, 2019.

FLIEGER, Verlyn. Splintered Light: Logos and Language in Tolkien's World. 2nd Revised Edition. Kent: Kent State University Press, 2002. 
FREER, Scott. The Mythical method: Eliot's 'the waste land' and a Canterbury Tale (1944). Historical Journal of Film, Radio and Television, v. 27, n. 3, p. 357-370, 2007.

GARBOWSKI, Christopher. “Evill”. In: LEE, Stuart D. (Ed.). A Companion to J. R. R. TOLKIEN. New Jersey: Wiley-Blackwell, 2014.

HARRISON, Andrew. Michael Moorcock: "I think Tolkien was a crypto-fascist". New Statesman, Londres, p. 1-1, 24 jul. 2015. Disponível em: <https://www.newstatesman.com/culture/2015/07/ michael-moorcock-i-think-tolkien-was-crypto-fascist>. Acesso em: 03 jul. 2020.

HILEY, Margaret. Stolen Language, Cosmic Models: myth and mythology in Tolkien. Mfs Modern Fiction Studies, v. 50, n. 4, p. 838-860, 2004. Project Muse.

HOUGHTON, John William; KEESEE, Neal K. Tolkien, King Alfred, and Boethius: Platonist Views of Evil in the Lord of the Rings. Tolkien Studies, v. 2, n. 1, p. 131-159, 2005. Project Muse. KERMODE, Frank (Ed.). Selected Prose of T. S. Eliot. London: Faber, 1975.

KIRK, Russell. A era de T. S. Eliot. A imaginação moral no século XX. São Paulo: É Editora, 2011. KLAUTAU, Diego Genu. O Bem e o Mal na Terra-Média - A filosofia de Santo Agostinho em O Senhor dos Anéis de J. R. R. Tolkien como crítica à modernidade. 2007. Dissertação (Ciências da Religião) - Programa de Pós-Graduação em Ciências da Religião da Pontifícia Universidade Católica de São Paulo, São Paulo, 2007.

KLAUTAU, Diego Genu. Tolkien e suas referências. In: CASAGRANDE, Cristina; KLAUTAU, Diego Genu, CUNHA; Maria Zilda da (Orgs.). A fabricação de mundos. Estudos sobre a literatura de J. R. R. Tolkien. São Paulo: FFLCH/USP, 2019. p. 15-54.

LEWIS, C. S. O Senhor dos Anéis, de Tolkien. Sobre histórias. Rio de Janeiro: Thomas Nelson, 2018. MOONEY, Chris. Kicking the Hobbit. The American Prospect, Washington, D.C., p. 1-1. 05 nov. 2001. Disponível em: <https://prospect.org/features/kicking-hobbit/>. Acesso em: 06 jul. 2020. MOORCOCK, Michael. Epic Pooh. 1978. Disponível em: <https://warwick.ac.uk/fac/arts/ english/currentstudents/undergraduate/modules/en361 fantastika/bibliography/2.7moorcock_m .1978epic_pooh.pdf>. Acesso em: 10 jul. 2020.

MORETTI, Franco. The Way of the World: The Bildungsroman in European Culture. Nova York: Verso, 2000.

SHIPPEY, Tom. The Road to Middle-Earth: How J. R. R. Tolkien Created a New Mythology. New York: Mariner Books, 2017.

TOLKIEN, J. R. R. The Monsters and the Critics and Other Essays. London: HarperCollins, 1990.

TOLKIEN, J. R. R. The Lord of the Rings. A Foreword to the Second Edition. Nova York: Harper Collins, 1995.

TOLKIEN, J. R. R. O Senhor dos Anéis. A Sociedade do Anel. São Paulo: Martins Fontes, 2000.

TOLKIEN, J. R. R. O Senhor dos Anéis. O Retorno do Rei. São Paulo: Martins Fontes, 2001.

TOLKIEN, J. R. R. O Silmarillion. São Paulo: Martins Fontes, 2002.

TOLKIEN, J. R. R. O Hobbit. Trad. Lenita Maria Rímoli Esteves e Almiro Pisetta. São Paulo: Martins Fontes, 2002.

TOLKIEN, J. R. R. Sobre histórias de fadas. São Paulo: Conrad, 2006.

TOLKIEN, J. R. R. Mythopoeia. Disponível em: <http://home.agh.edu.pl/ evermind/jrrtolkien/ mythopoeia.htm>.

TYLER, J. E. A. The Tolkien Companion. New York: Avon Books, 1977.

WOOD, Ralph C. The Gospel According to Tolkien. Visions of the Kingdom in Middle-earth. Louisville: Westminster John Knox, 2003. 